\title{
Commuting mode and pulmonary function in Shanghai, China
}

\author{
Adam W. Gaffney ${ }^{1}$, Jing-qing Hang ${ }^{2}$, Mi-Sun Lee ${ }^{3}$, Li Su ${ }^{3}$, Feng-ying Zhang ${ }^{2}$ and \\ David C. Christiani ${ }^{1,3,4}$ \\ Affiliations: 'Massachusetts General Hospital, Boston, MA, USA. ${ }^{2}$ Shanghai Putuo District People's Hospital, \\ Shanghai, China. ${ }^{3}$ Environmental and Occupational Medicine and Epidemiology Program, Dept of \\ Environmental Health, Harvard T.H. Chan School of Public Health, Boston, MA, USA. "Harvard Medical School, \\ Boston, MA, USA.
}

Correspondence: Adam W. Gaffney, Massachusetts General Hospital, 55 Fruit Street, Boston, MA 02114, USA. E-mail: agaffneydpartners.org

ABSTRACT Exposure to air pollution can be particularly high during commuting and may depend on the mode of transportation. We investigated the impact of commuting mode on pulmonary function in Shanghai, China.

The Shanghai Putuo Study is a cross-sectional, population-based study. Our primary outcomes were forced expiratory volume in $1 \mathrm{~s}(\mathrm{FEV} 1)$ and forced vital capacity (FVC) \% predicted, and the secondary outcome was spirometric airflow obstruction. We tested the association between mode of transportation and these outcomes after adjusting for confounders.

The study population consisted of 20102 subjects. After adjusting for confounders, the change (95\% CI) in $\mathrm{FEV}_{1}$ was $-2.15 \%$ pred $(-2.88--1.42 \%$ pred) among pedestrians, $-1.32 \%$ pred $(-2.05--0.59 \%$ pred $)$ among those taking buses without air conditioning, $-1.33 \%$ pred $(-2.05--0.61 \%$ pred $)$ among those taking buses with air conditioning and $-2.83 \%$ pred $(-5.56--0.10 \%$ pred) among those using underground railways, as compared to cyclists (the reference group). The effects of mode on FVC \% predicted were in the same direction. Private car use had a significant protective effect on FVC \% predicted and the risk of airflow obstruction (defined by Global Initiative for Chronic Obstructive Lung Disease but not by lower limit of normal criteria).

Mode of transportation is associated with differences in lung function, which may reflect pollution levels in different transportation microenvironments.

@ERSpublications

In Shanghai, China, certain modes of commuting to work are associated with reductions in pulmonary function http://ow.ly/TlyKT

This article has supplementary material available from erj.ersjournals.com

Received: April 222015 | Accepted after revision: Sept 242015 | First published online: Nov 052015

Support statement: This study was supported by the US National Institutes of Health (grants T32 HL116275 and NIEHS ES00002) and the Shanghai Putuo District People's Hospital. The study sponsors had no role in the study design, analysis or manuscript preparation. Funding information for this article has been deposited with FundRef.

Conflict of interest: Disclosures can be found alongside the online version of this article at erj.ersjournals.com

The content of this work is copyright of the authors or their employers. Design and branding are copyright (CERS 2016. 


\section{Introduction}

Modern modes of transportation have revolutionised the movement of goods and people across the globe, while simultaneously imposing novel threats to the health of the public. In particular, a growing body of evidence implicates exposure to traffic-related air pollution (TRAP), as assessed by residential location, as a cause of adverse cardiopulmonary health effects [1-6]. However, there is also evidence to suggest that exposure to TRAP during commuting may constitute an additional environmental health hazard.

Pollution levels within the "transport microenvironment" during a commute, for instance, are substantially greater than the levels recorded by background urban monitors $[7,8]$. Furthermore, exposures to different commuting environments have short-term and potentially adverse biological effects in some studies [9-12]. The impact of the commuting exposure, however, may depend on the specific transport microenvironment utilised. One review, for instance, found a variable exposure to ultrafine particle concentration among various common modes of urban transportation [13].

Overall, however, the implications of the mode of commuting on pulmonary function remain unclear and we are aware of no large-scale studies evaluating this association. The public health implications of this question are important, particularly in low- and middle-income countries that are undergoing tremendous changes in their transportation infrastructure and motorisation $[14,15]$. We therefore used data from a large population-based study in China to study the effect of commuting mode on pulmonary function and airflow obstruction.

\section{Material and methods}

\section{Study subjects and study design}

All study subjects were enrolled in the Shanghai Putuo Study, a cross-sectional, population-based study performed in the Putuo District of Shanghai, China. The project is a collaboration between the Shanghai District People's Hospital and the Harvard T.H. Chan School of Public Health (Boston, MA, USA), and the Institutional Review Boards (IRBs) of both approved the study (Harvard T.H. Chan School of Public Health IRB protocol \#CR-14777-01). The study was performed in compliance with the 2013 revision of the Declaration of Helsinki. The details of the study have been previously published $[16,17]$. Briefly, participants were randomly selected on the basis of census tract. Study subjects were recruited between August 2007 and January 2010, and those who provided written performed consent underwent an interview and spirometry.

Of the 37690 subjects contacted, 27042 provided informed consent to participate. Of these, 1819 were $<18$ years of age and so were excluded (figure 1). Of the remaining 25223 subjects, we excluded 1091 with missing spirometry and 380 with an unacceptably high coefficient of variation (>20\%). 522 subjects with missing data on the main covariates (e.g. age, sex, height, second-hand smoke (SHS) exposure, pack-years or smoking status, biomass exposure, education, or occupation) were then excluded. Notably, only a minority of participants ( $\mathrm{n}=8684$ at this stage in the cohort formation) answered a question about dust exposure at the workplace. We excluded the 86 subjects who answered in the affirmative. Next, subjects with missing $(n=335)$ or no $(n=8)$ reported modes of transportation were also excluded. Finally, because the aim of the study was to compare the effect of specific modes of transportation against other modes, we excluded subjects who reported more than one mode of transportation ( $n=2699$ ), leaving 20102 subjects for the final analysis.

\section{Methods}

All subjects underwent an interview, which involved completion of a health questionnaire administered by personnel who were trained and tested in its use. All subjects were asked (in Chinese) "How do you go to and come back from work?" and could choose one or more of the following modes: bus without air conditioning, bus with air conditioning, bicycle, scooter, taxi, car from the company, private car, train, underground train and walking.

Spirometry was performed according to American Thoracic Society guidelines [18]. Measurement of forced expiratory volume in $1 \mathrm{~s}$ (FEV1), forced vital capacity (FVC) and peak expiratory flow was performed with the subjects in the seated position. A hand-held spirometer (Micro plus; Micro Ltd., Rochester, UK) was used for all measurements. Spirometers were calibrated daily using a 3-L syringe. Spirometry was performed at the same time as questionnaire completion and physical examination between 07:00 and 16:00 h, at the convenience of the study subject. The highest FEV1 and FVC were recorded after performance of at least three acceptable efforts. FEV1 and FVC were measured in litres and then converted to \% predicted using a prediction equation validated for an adult Chinese population [19]. An acceptable FVC had to be sustained for at least $6 \mathrm{~s}$. Measurements were repeated if the two highest FEV1 and FVC manoeuvers were not within $10 \%$ of each other. However, the reproducibility of efforts was also assessed retrospectively by the coefficient of variation, calculated by dividing the standard deviation of the FVC by its mean and multiplying by 100 . Following previous studies $[17,20,21]$, a coefficient of variation of $<20 \%$ was used as evidence of reproducibility. Subjects who did not meet this reproducibility 


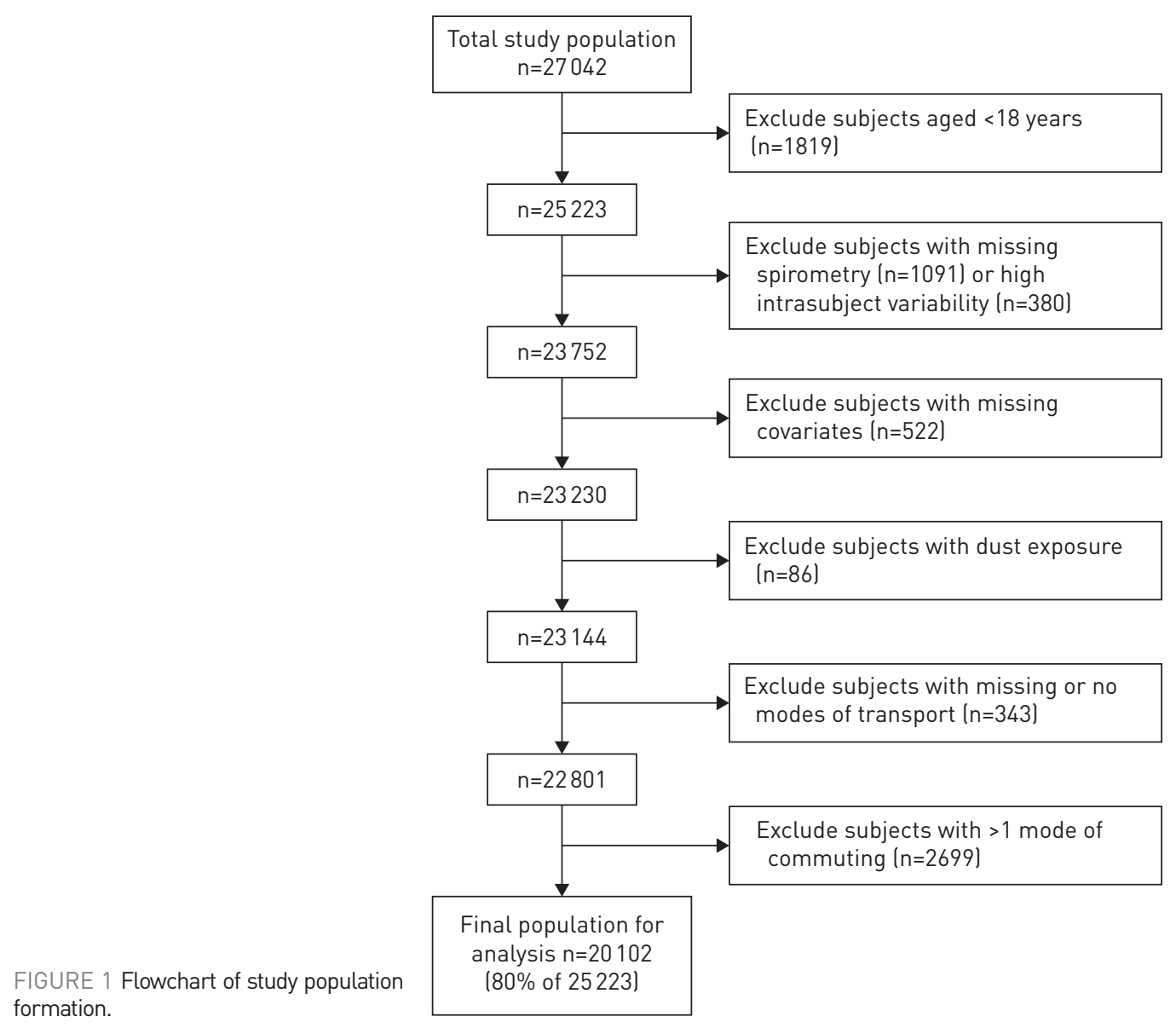

criterion were excluded from our analysis, as detailed later. Notably, though study personnel performing spirometry were not specifically blinded to the results of the questionnaire, they were unaware of the specific hypothesis of this present study. Mode of transportation was one of a very large number of questions collected in the study questionnaire and so there is no plausible way that mode of transportation would affect the personnel's performance of spirometry.

\section{Analysis}

All statistical analyses were performed using SAS version 9.4 (SAS Institute Inc., Cary, NC, USA). FEV1 $\%$ predicted and FVC \% predicted were the primary outcome measures. The mode of transportation was the predictor of interest. Multiple linear regressions were used to assess the association between the mode of transportation and the primary outcome measures. The absence or presence of airflow obstruction, defined both by Global Initiative for Chronic Obstructive Lung Disease (FEV1/FVC ratio <0.70) and by lower limit of normal (LLN) criteria, was a secondary outcome assessed with logistic regression. Cyclists, who may have lower exposure to pollutants as compared to those in cars and buses [7, 13, 22, 23] and perhaps, but not consistently, as compared to pedestrians [13], constituted the largest commuting category and were chosen as the reference group for all regressions.

Multiple covariates were treated as potential confounders in the final models, including age (years), sex, SHS exposure (yes/no), home biomass fuel use (yes/no), smoking status (current, former or never), pack-years of smoking, education (elementary school or lower, middle or high school, or college or higher) and occupation (farmer, worker, professional, administrator, services, household, retired or other). The logistic models for airflow obstruction were additionally adjusted for height. Adjustment for occupation was our primary method for controlling for workplace exposure.

We conducted a number of sensitivity analyses. For occupational status, we conducted three sensitivity analyses, excluding first retirees, then retirees and household workers, and finally retirees, household workers, and those with "other" occupation. We also conducted an analysis restricted to never-smokers, an analysis that included those with more than one mode of transportation and subgroup analyses looking at specific educational strata. 


\section{Results}

Characteristics of the study population stratified by mode of transportation are reported in table 1 . The overall study population of 20102 subjects had a mean age of 49 years and was $54 \%$ female. Bicycling was the most frequent form of transportation $(n=5154)$, followed by bus with air conditioning $(n=3650)$ and then by walking $(n=3220)$. Some modes of transportation were utilised by very few study subjects, including taxi $(n=127)$, company car $(n=325)$, underground $(n=138)$ and train $(n=18)$. The reference group (cyclists) had an above-average mean age of 54 years, were comparatively frequent ever-users of biomass (90.4\%), had a higher rate of current smoking (27.5\%) and had a lower education level as compared to the overall population.

The adjusted estimates of \% predicted FEV1 and FVC are reported in table 2 . As compared with the reference group (cyclists), several groups had statistically significant reductions in $\mathrm{FEV}_{1} \%$ predicted after adjusting for all confounders. The change (95\% CI) in FEV1 was $-2.15 \%$ pred $(-2.88--1.42 \%$ pred) among pedestrians, $-1.32 \%$ pred $(-2.05--0.59 \%$ pred) among those taking the bus without air conditioning, $-1.33 \%$ pred $(-2.05--0.61 \%$ pred $)$ among those taking the bus with air conditioning and $-2.83 \%$ pred $(-5.56--0.10 \%$ pred) among those using underground railways. Private car use had a protective effect, with a $0.91 \%$ pred higher FEV1 (95\% CI $-0.02-1.85 \%$ pred), as compared to cyclists, that trended towards statistical significance $(\mathrm{p}=0.06)$. Effects of mode of transportation on FVC \% predicted were in the same direction. Statistically significant reductions in FVC \% predicted emerged among those taking the bus without air conditioning $(-1.04 \%$ pred, 95\% CI $-1.73--0.36 \%$ pred), those taking the bus with air conditioning $(-1.54 \%$ pred, $95 \%$ CI $-2.21--0.87 \%$ pred) and pedestrians $(-2.79 \%$ pred, $95 \%$ CI $-3.48--2.11 \%$ pred). Private car use had statistically significant higher FVC \% predicted compared to cyclists ( $0.95 \%$ pred, $95 \%$ CI $0.07-1.82 \%$ pred).

The adjusted associations of mode of transportation with airflow obstruction are given in table 3 . We found a reduced risk of airflow obstruction, defined as an FEV1/FVC ratio $<0.70$ (OR 0.43, 95\% CI 0.21-0.86), among private car users as compared to cyclists. When obstruction was defined by LLN criteria, private car users also had a reduced risk of obstruction (OR $0.68,95 \%$ CI $0.41-1.12$ ), though this was not statistically significant. No other statistically significant differences in airflow obstruction were noted between cyclists and the other groups.

Additionally, a number of sensitivity analyses was conducted. Though only subjects who answered the question "How do you go to and come back from work?" were included in our analysis, the meaning of this question for those with retired $(n=8294)$, household duties $(n=341)$ or "other" $(n=1917)$ occupational status was not entirely clear. We therefore first conducted a sensitivity analysis excluding retirees only (table S1). In this analysis $(\mathrm{n}=11808)$, our overall results remained robust. Both bus riders and pedestrians still had a statistically significant reduction in both FEV1 and FVC \% predicted as compared to cyclists. Private car use had a statistically significant protective effect on both FEV1 and FVC \% predicted as compared to cyclists, while the significant effect of subway riding was lost. After additionally excluding those with household duties (table S2), reductions in both FEV1 and FVC \% predicted remained significant for both bus riders and pedestrians. The protective effect of private car use was significant for FVC \% predicted only, while a significant reduction in FEV1 \% predicted was seen among company car users. Finally, after additionally excluding those with "other" occupational status (table 3), our overall results remained robust $(\mathrm{n}=9550)$. The significant reductions in both $\mathrm{FEV}_{1}$ and FVC \% predicted for both groups of bus riders and walkers remained, as did the protective effect of private car use on FVC \% predicted. A reduced $\mathrm{FEV}_{1} \%$ predicted was seen among those using company cars. The significant effect of subway use did not persist in any of these three sensitivity analyses.

When those who listed more than one mode of transport were treated as a separate group and included in the final model (total $n=22801$ ), the overall results were again generally stable (table S4). When we restricted our analysis to never-smokers $(n=14719)$ to reduce the likelihood of residual confounding by smoking, most of the statistically significant associations remained for bus riders, pedestrians and private car users (table S5). Notably, however, there was no effect of underground train or company car use. We also performed an analysis restricting our analysis to each of the two larger educational categories separately (elementary school or lower, and middle or high school), so as to reduce the likelihood of residual confounding by socioeconomic status (SES). When we confined our analysis to the lowest educational stratum $(n=7643)$, the confidence intervals widened for many of our results and the majority of the statistically significant associations were lost (table S6). However, walking remained significantly associated with both a reduced FEV1 and FVC \% predicted as compared to cyclists. When the analysis was restricted to subjects with intermediate education levels $(n=9080)$, the direction of the majority of the effects was stable compared to our primary analysis (table S7). Walking and bus with air conditioning (but not without air conditioning) were still significantly associated with both reduced FEV1 and FVC \% predicted. The protective effect of private car use on FEV1 and FVC \% predicted was no longer statistically significant ( $\mathrm{p}=0.06$ and $\mathrm{p}=0.08$, respectively), while a significant protective effect of taxi use on FVC \% predicted emerged. 
TABLE 1 Characteristics of the study population, stratified by commuting mode $(n=20102)$

\begin{tabular}{|c|c|c|c|c|c|c|c|c|c|c|c|}
\hline & \multirow[t]{2}{*}{ Total } & \multicolumn{10}{|c|}{ Commuting mode } \\
\hline & & Bus without AC & Bus with AC & Scooter & Taxi & Company car & Private car & Train & Underground train & Walking & Bicycle \\
\hline Subjects & $20102(100)$ & $2945(14.7)$ & $3650(18.2)$ & $2612(13.0)$ & $127(0.6)$ & $325(1.6)$ & $1913(9.5)$ & $18(0.1)$ & $138(0.7)$ & $3220(16.0)$ & $5154(25.6)$ \\
\hline Age years & $49.0 \pm 16.4$ & $52.0 \pm 17.7$ & $41.6 \pm 15.8$ & $41.0 \pm 11.5$ & $39.7 \pm 9.6$ & $47.4 \pm 12.1$ & $37.8 \pm 9.6$ & $28.8 \pm 5.9$ & $30.2 \pm 8.9$ & $61.3 \pm 15.5$ & $54.1 \pm 13.0$ \\
\hline Females & $10880(54.1)$ & $1947(66.1)$ & $2391(65.5)$ & $943(36.1)$ & $30(23.6)$ & $43(13.2)$ & 665 (34.8) & $7(38.9)$ & $70(50.7)$ & 2377 (73.8) & $2407(46.7)$ \\
\hline \multicolumn{12}{|l|}{ Smoking } \\
\hline Current & $4613(23.0)$ & $401(13.6)$ & 520 (14.3) & 1015 (38.9) & $67(52.8)$ & 169 (52.0) & 617 (32.3) & $4(22.2)$ & $16(11.6)$ & 387 (12.0) & 1417 (27.5) \\
\hline Former & $770(3.8)$ & 87 (3.0) & $63(1.7)$ & $76(2.9)$ & $3(2.4)$ & 18 (5.5) & $46(2.4)$ & $0(0.0)$ & $1(0.7)$ & $146(4.5)$ & $330(6.4)$ \\
\hline Never & 14719 (73.2) & 2457 (83.4) & $3067(84.0)$ & $1521(58.2)$ & 57 (44.9) & 138 (42.5) & $1250(65.3)$ & 14 (77.8) & $121(87.7)$ & 2687 (83.5) & $3407(66.1)$ \\
\hline Smoking " pack-years & $26.3 \pm 36.4$ & $25.5 \pm 26.7$ & $22.6 \pm 35.4$ & $21.4 \pm 25.3$ & $28.4 \pm 46.1$ & $31.0 \pm 59.9$ & $19.9 \pm 29.4$ & $20.9 \pm 32.9$ & $14.0 \pm 11.1$ & $33.9 \pm 53.6$ & $30.5 \pm 36.4$ \\
\hline \multicolumn{12}{|l|}{ Education } \\
\hline $\begin{array}{l}\text { Elementary school } \\
\text { or lower }\end{array}$ & $7643(38.0)$ & 1154 (39.2) & 690 (18.9) & $679(26.0)$ & $26(20.5)$ & 53 (16.3) & $168(8.8)$ & $0.0(0.0)$ & $5(3.6)$ & 2247 (69.8) & $2621(50.9)$ \\
\hline Middle/high & $9080(45.2)$ & $1321(44.9)$ & $2002(54.9)$ & 1549 (59.3) & $70(55.1)$ & 188 (57.9) & 928 (48.5) & $10(55.6)$ & 59 (42.8) & 800 (24.8) & 2153 (41.8) \\
\hline College or higher & 3379 (16.8) & $470(16.0)$ & 958 (26.3) & $384(14.7)$ & $31(24.4)$ & 84 (25.9) & 817 (42.7) & $8(44.4)$ & $74(53.6)$ & $173(5.4)$ & $380(7.4)$ \\
\hline SHS ever & 14985 (74.5) & 2134 (72.5) & $2590(71.0)$ & $2068(79.2)$ & $92(72.4)$ & 248 (76.3) & $1388(72.6)$ & 14 (77.8) & 77 (55.8) & $2337(72.6)$ & 4037 (78.3) \\
\hline Biomass use ever & 16212 (80.7) & 2442 (82.9) & $2617(71.7)$ & $2012(77.0)$ & $94(74.0)$ & 264 (81.2) & $1133(59.2)$ & $9(50.0)$ & $71(51.5)$ & 2913 (90.5) & $4657(90.4)$ \\
\hline \multicolumn{12}{|l|}{ Occupation } \\
\hline Farmer & $108(0.5)$ & $3(0.1)$ & $2(0.1)$ & $4(0.2)$ & $0(0.0)$ & $0(0.0)$ & $2(0.1)$ & $0(0)$ & $0(0)$ & $80(2.5)$ & $17(0.3)$ \\
\hline Worker & $1199(6.0)$ & $131(4.5)$ & $167(4.6)$ & 307 (11.8) & $3(2.4)$ & $14(4.3)$ & $34(1.8)$ & $0(0)$ & $1(0.72)$ & $112(3.5)$ & 430 (8.3) \\
\hline Professional & $4338(21.6)$ & $501(17.0)$ & $1002(27.5)$ & $963(36.9)$ & 79 (62.2) & $150(46.2)$ & 778 (40.7) & $10(55.6)$ & $60(43.5)$ & $186(5.8)$ & 609 (11.8) \\
\hline Administrator & $2560(12.7)$ & 243 (8.3) & 504 (13.8) & 497 (19.0) & $20(15.8)$ & $88(27.1)$ & 800 (41.8) & $4(22.2)$ & $41(29.7)$ & $99(3.1)$ & $264(5.1)$ \\
\hline Services & $1345(6.7)$ & $119(4.0)$ & $246(6.7)$ & $371(14.2)$ & $14(11.0)$ & $4(1.2)$ & $52(2.7)$ & $1(5.6)$ & $9(6.5)$ & $133(4.1)$ & $396(7.7)$ \\
\hline Household & 341 (1.7) & $24(0.8)$ & $71(2.0)$ & $19(0.7)$ & $0(0)$ & $0(0)$ & $4(0.2)$ & $0(0)$ & $0(0)$ & 138 (4.3) & $85(1.7)$ \\
\hline Retired & 8294 (41.3) & 1639 (55.7) & $1140(31.2)$ & $250(9.6)$ & $1(0.8)$ & $57(17.5)$ & $44(2.3)$ & $0(0.0)$ & $2(1.5)$ & $2312(71.8)$ & 2849 (55.3) \\
\hline Other & 1917 (9.5) & 285 (9.7) & $518(14.2)$ & $201(7.7)$ & $10(7.9)$ & $12(3.7)$ & $199(10.4)$ & $3(16.7)$ & $25(18.1)$ & $160(5.0)$ & 504 (9.8) \\
\hline FEV $1 \%$ predicted & $97.8 \pm 16.4$ & $97.9 \pm 17.6$ & $98.9 \pm 14.7$ & $98.0 \pm 14.0$ & $98.6 \pm 11.9$ & $96.7 \pm 13.9$ & $99.8 \pm 13.2$ & $96.0 \pm 14.0$ & $97.7 \pm 12.7$ & $96.2 \pm 19.6$ & $97.3 \pm 16.9$ \\
\hline FVC \% predicted & $89.0 \pm 16.1$ & $88.9 \pm 17.2$ & $91.6 \pm 14.7$ & $90.4 \pm 14.2$ & $92.2 \pm 14.2$ & $88.4 \pm 14.3$ & $93.5 \pm 13.5$ & $90.9 \pm 12.8$ & $94.1 \pm 14.0$ & $84.3 \pm 18.0$ & $87.6 \pm 16.3$ \\
\hline
\end{tabular}


TABLE 2 Adjusted estimates for \% predicted forced expiratory volume in $1 \mathrm{~s}$ (FEV1) and forced vital capacity (FVC) associated with mode of transportation

\begin{tabular}{lccccc} 
Mode of transport & \multicolumn{2}{c}{ FEV $\%$ predicted } & & \multicolumn{2}{c}{ FVC \% predicted } \\
\cline { 2 - 3 } \cline { 5 - 6 } & Effect estimate $(\mathbf{9 5 \%}$ CI) & p-value & & Effect estimate (95\% CI) & p-value \\
\hline Bus without AC & $-1.32(-2.05--0.59)$ & $<0.01$ & & $-1.04(-1.73--0.36)$ & $<0.01$ \\
Bus with AC & $-1.33(-2.05--0.61)$ & $<0.01$ & & $-1.54(-2.21--0.87)$ & $<0.01$ \\
Scooter & $-0.13(-0.93-0.67)$ & 0.76 & & $-0.63(-1.38-0.11)$ & 0.10 \\
Taxi & $0.87(-1.96-3.69)$ & 0.55 & & $1.19(-1.46-3.83)$ & 0.38 \\
Company car & $0.11(-1.71-1.92)$ & 0.91 & & $0.10(-1.59-1.80)$ & 0.90 \\
Private car & $0.91(-0.02-1.85)$ & 0.06 & & $0.95(0.07-1.82)$ & 0.03 \\
Train & $-3.90(-11.27-3.47)$ & 0.30 & & $-4.53(-11.42-2.37)$ & 0.20 \\
Underground train & $-2.83(-5.56--0.10)$ & 0.04 & & $-1.72(-4.27-0.84)$ & 0.19 \\
Walking & $-2.15(-2.88--1.42)$ & $<0.01$ & & $-2.79(-3.48--2.11)$ & $<0.01$ \\
Bicycle & Reference & & & Reference &
\end{tabular}

Adjusted for age, sex, second-hand smoke exposure (yes or no), pack-years, smoking status (current, former or never), biomass exposure (yes or no), education (elementary school or lower, middle or high school, or college or higher), mode of transport and occupational category (farmer, worker, professional, administrator, services, household duties, retired or other). AC: air conditioning.

\section{Discussion}

Motor vehicles release a complex mixture of pollutants and serve as an important cause of spatial differences in air pollution within the urban environment [1]. In addition to the potential risks of residential TRAP exposure, it is plausible that commuting TRAP exposure may have additional adverse effects. This is supported by data demonstrating that commuting exposures may trigger both systemic and pulmonary inflammation. For instance, short-term traffic and transport exposures have been associated with nonfatal myocardial infarction [24], increased exhaled nitrous oxide [25], elevated blood fibrinogen levels [10], reductions in FEV1 and FVC, increased biomarkers of neutrophilic inflammation in sputum, reductions in exhaled breath condensate $\mathrm{pH}$ [12], and increases in bronchoalveolar lavage cell counts [26]. However, one study performed in Australia found that lower versus higher pollution cycling routes resulted in short-term differences in subject symptoms but not in differences in peak flow or sputum neutrophilia, suggesting that not all differences in pollution exposure have immediate biological effects [27].

The pollution exposure faced by a commuter can be conceived as the result of a complex interaction of multiple factors including site characteristics (e.g. background ambient pollution), mode of transportation,

TABLE 3 Adjusted risk of airway obstruction (forced expiratory volume in $1 \mathrm{~s}$ (FEV1)/forced vital capacity (FVC) $<70 \%$ and FEV1/FVC below the lower limit of normal (LLN)) associated with mode of transportation $(n=20102)$

\begin{tabular}{|c|c|c|c|c|}
\hline & \multicolumn{2}{|c|}{ FEV $_{1} /$ FVC $<70 \%$} & \multicolumn{2}{|c|}{ FEV $1 / F V C<L L N$} \\
\hline & $\mathrm{OR}^{\#}(95 \% \mathrm{CI})$ & p-value & $\mathrm{OR}^{\#}(95 \% \mathrm{CI})$ & p-value \\
\hline Bus without AC & $1.04(0.76-1.43)$ & 0.81 & $1.12(0.79-1.59)$ & 0.51 \\
\hline Bus with AC & $0.79(0.54-1.15)$ & 0.21 & $1.06(0.75-1.49)$ & 0.76 \\
\hline Scooter & $0.71(0.44-1.13)$ & 0.15 & $0.85(0.56-1.27)$ & 0.42 \\
\hline Taxi & $2.11(0.64-6.91)$ & 0.22 & $2.21(0.78-6.25)$ & 0.14 \\
\hline Company car & $0.72(0.26-2.01)$ & 0.53 & $1.10(0.43-2.77)$ & 0.85 \\
\hline Private car & $0.43(0.21-0.86)$ & 0.02 & $0.68(0.41-1.12)$ & 0.13 \\
\hline Train & ก & ก & ก & ๆ \\
\hline Underground train & $0.82(0.11-6.09)$ & 0.85 & $1.50(0.53-4.28)$ & 0.44 \\
\hline Walk & $0.92(0.67-1.25)$ & 0.57 & $1.00(0.70-1.42)$ & 0.98 \\
\hline Bicycle & Reference & Reference & & \\
\hline
\end{tabular}

AC: air conditioning. ${ }^{\#}$ : adjusted for age, height, gender, second-hand smoke (yes or no), smoking history (current, former or never), pack-years of smoking, biomass exposure (yes or no), education (elementary school or lower, middle or high school, or college or higher), mode of transport and occupational category (farmer, worker, professional, administrator, services, household duties, retired or other); ": exhibited nonconvergence, OR $(95 \% \mathrm{CI})$ and $\mathrm{p}$-value not reported. 
vehicle characteristics such as ventilation system [28-30] and fuel type [8], and route characteristics (e.g. traffic density and route length). Given these multiple factors, it is not surprising that there is some inconsistency on the relationship between mode of transport and pollutant concentrations in the literature. One 2007 review, for instance, found that commuting within a vehicle, as opposed to via cycling or walking, seemed to be associated with higher levels of particulate matter exposure [7]. Cyclists in particular have had lower pollution exposures than those in cars and buses in several studies [13, 22, 23, 31]. Although presumably exposed to the same ambient environment, the relative exposure of walkers seems more variable. In a review relying on data from 47 studies, for instance, KNIBBS et al. [13] found higher ultrafine particle exposures for pedestrians than for those using rail, automobile, bus or bicycle (which had the lowest). A number of recent studies, including one in Hanoi, Vietnam, have similarly found pedestrians to be exposed to higher levels of particulate air pollution than those in cars or buses $[28,32,33]$, though one earlier study found the opposite [31]. The pollutant concentration itself, however, is not the only factor. Because of the higher minute ventilation required for cycling (or walking), it is also possible that such commuters may actually be exposed to a higher inhaled dose of pollutants [8].

Some of our findings are consistent with this incomplete literature. For instance, we found that those walking to work had consistent statistically significant reductions in FEV1 and FVC, which may be the result of the higher pollution exposure in this microenvironment. For instance, one study in urban Guangzhou, China, found that pedestrians were exposed to high concentrations of particulate material $<10 \mu \mathrm{m}$ in diameter, which exceeded the levels found in public transport [34]. Similarly, we found largely consistent significant reductions in lung function in those taking the bus as compared to cyclists, a finding which may again also be explained by elevated within-bus pollution as seen in some studies [13, 23]. The cause of reduced lung function in pedestrians compared to cyclists, however, is less apparent. One possibility is that walkers are somehow exposed to higher levels of certain pollutants than cyclists, which as discussed above, has been demonstrated in some studies. Given that cycling may require greater coordination and health status than walking, it is also conceivable that the higher lung function of cyclists as compared to walkers is the result of a confounding "healthy cyclist" effect. Finally, the apparently protective effect of private car use as compared to cyclists is not clearly consistent with the literature on pollution concentrations. Indeed, we found that cyclists had an elevated risk of airflow obstruction compared to those using a private car, although only when defined by GOLD, and not by LLN, criteria. One possibility, however, is that the increased minute ventilation required for cycling elevates the inhaled dose of pollutants so as to outweigh the lower pollutant concentrations seen by cyclists in some studies [8]. For instance, in one study that directly measured the respiratory parameters of study subjects, despite exposure to similar overall concentrations of pollutants, cyclists (as compared to car passengers) had much higher inhaled quantities of pollutants as a result of having a greater than four-fold higher minute ventilation [35]. Finally, it is important to emphasise that the significant differences that emerged in some analyses (but not others) for company car, taxi use and underground use were variable and highly inconsistent in sensitivity analysis. Particularly in light of the very small numbers of users of these vehicles in this study, we do not believe that any conclusions should be drawn for those three modes of transportation from this study.

We acknowledge that our study has some strengths and some weaknesses. It is a large-scale, population-based study with an objective outcome. We were able to control for multiple important potential confounders, including occupation. There were also proportionally few subjects excluded for missing data. The most important limitation of this study is its cross-sectional design, which limits our ability to draw causal inferences. Some of the findings, however, are unlikely to be explained by reverse causality. For instance, there is no obvious reason why individuals who developed reduced lung function or airflow obstruction would stop driving and start cycling (or walking) to work. Confounding by unmeasured variables is always an additional concern in observational studies. For instance, in this study, we were unable to adjust for family history of lung disease, as this information was not in our questionnaire. However, for this genetic factor to function as a confounder, it would have to be related to not only lung function but also to mode of commuting, which seems highly improbable. Another concern relates to the possibility of residual confounding by SES, which is known to be related to lung function [36]. Notably, despite substantial reductions in power, some of our results remained significant after restricting the analysis to individual SES categories (e.g. for pedestrians). Additionally, we would expect that residual SES confounding might have biased some (but not all) of our other findings towards the null (for instance, we found that cyclists had higher lung function than bus riders, despite being less educated). Another concern relates to the fact that the exposure was determined as the mode of commuting used to get to work as ascertained at the time the survey was performed; it therefore may not reflect modes of transportation previously used, as well as secular trends in ambient pollution exposure over the course of subjects' lives. It should be similarly emphasised that the differences we found may not necessarily be the result of the mode of commuting itself but of various other factors associated with that mode, such as characteristics of the route used. Finally, given differences in the transportation and urban milieu among cities, it would be important to repeat this analysis in different urban environments. 
It is important to note that although our results were statistically significant, many of the effect estimates for FEV1 and FVC \% predicted were small, and would be of marginal clinical significance on the individual level. However, even relatively small shifts in the distribution of a risk factor for disease, like blood pressure, can result in substantial aggregate harm or benefit at the population level [37]. Likewise, the impact on pulmonary function of a nearly ubiquitous exposure like commuting may, in aggregate, be substantial.

Thus, considered together with other studies, this investigation may have important public health ramifications. Urbanisation is being accompanied by a tremendous trend towards motorisation in nations such as China and India $[14,15,38]$. In addition to increasing the risk of road injury [39], motorisation will probably be accompanied by increasing TRAP production. Ironically, in this study, those contributing the least to roadway pollution (e.g. pedestrians and perhaps cyclists) may in fact be those most affected by it, while those contributing the most (e.g. private car users) may, in fact, be protected. At the same time, however, it is important to note that regular physical activity has beneficial effects for health on its own. Therefore, from our perspective, the solution lies not in the further acceleration of trends towards motorisation but instead in the reduction of TRAP production itself, so as to ensure a safe commuting environment for all.

\section{Conclusions}

In conclusion, in this large-scale, population-based study, we found that the mode of transportation used to commute to work was associated with differences in lung function, which may reflect differing levels of pollutants faced in the diverse transportation microenvironments.

\section{Acknowledgements}

The results of this study were previously presented at the American Thoracic Society conference in May 2015 (Denver, CO, USA).

\section{References}

1 Health Effects Institute. Traffic-Related Air Pollution: A Critical Review of the Literature on Emissions, Exposure, and Health Effects. Boston, Health Effects Institute, 2010.

2 Suglia SF, Gryparis A, Schwartz J, et al. Association between traffic-related black carbon exposure and lung function among urban women. Environ Health Perspect 2008; 116: 1333-1337.

3 Kan H, Heiss G, Rose KM, et al. Traffic exposure and lung function in adults: the Atherosclerosis Risk in Communities study. Thorax 2007; 62: 873-879.

4 Hoek G, Brunekreef B, Goldbohm S, et al. Association between mortality and indicators of traffic-related air pollution in the Netherlands: a cohort study. Lancet 2002; 360: 1203-1209.

5 Schikowski T, Sugiri D, Ranft U, et al. Long-term air pollution exposure and living close to busy roads are associated with COPD in women. Respir Res 2005; 6: 152.

6 Schikowski T, Mills IC, Anderson HR, et al. Ambient air pollution: a cause of COPD? Eur Respir J 2014; 43: 250-263.

7 Kaur S, Nieuwenhuijsen MJ, Colvile RN. Fine particulate matter and carbon monoxide exposure concentrations in urban street transport microenvironments. Atmos Environ 2007; 41: 4781-4810.

8 Zuurbier M, Hoek G, Oldenwening M, et al. Commuters' exposure to particulate matter air pollution is affected by mode of transport, fuel type, and route. Environ Health Perspect 2010; 118: 783-789.

9 Jacobs L, Nawrot TS, de Geus B, et al. Subclinical responses in healthy cyclists briefly exposed to traffic-related air pollution: an intervention study. Environ Health 2010; 9: 64.

10 Klepczynska Nystrom A, Svartengren M, Grunewald J, et al. Health effects of a subway environment in healthy volunteers. Eur Respir J 2010; 36: 240-248.

11 Sarnat JA, Golan R, Greenwald R, et al. Exposure to traffic pollution, acute inflammation and autonomic response in a panel of car commuters. Environ Res 2014; 133: 66-76.

12 McCreanor J, Cullinan P, Nieuwenhuijsen MJ, et al. Respiratory effects of exposure to diesel traffic in persons with asthma. N Engl J Med 2007; 357: 2348-2358.

13 Knibbs LD, Cole-Hunter T, Morawska L. A review of commuter exposure to ultrafine particles and its health effects. Atmos Environ 2011; 45: 2611-2622.

14 Pucher J, Peng Zr, Mittal N, et al. Urban transport trends and policies in China and India: impacts of rapid economic growth. Transport Rev 2007; 27: 379-410.

15 Huo H, Wang M. Modeling future vehicle sales and stock in China. Energy Policy 2012; 43: 17-29.

16 Lee MS, Hang JQ, Zhang FY, et al. In-home solid fuel use and cardiovascular disease: a cross-sectional analysis of the Shanghai Putuo study. Environ Health 2012; 11: 18.

17 Lee MS, Hang JQ, Zhang FY, et al. Household solid fuel use and pulmonary function in an urban population in Shanghai, China. Occup Environ Med 2013; 70: 120-125.

18 Standardization of Spirometry, 1994 Update. American Thoracic Society. Am J Respir Crit Care Med 1995; 152 : $1107-1136$.

19 Ip MS, Ko FW, Lau AC, et al. Updated spirometric reference values for adult Chinese in Hong Kong and implications on clinical utilization. Chest 2006; 129: 384-392.

20 Ramsey BW, Astley SJ, Aitken ML, et al. Efficacy and safety of short-term administration of aerosolized recombinant human deoxyribonuclease in patients with cystic fibrosis. Am Rev Respir Dis 1993; 148: 145-151.

21 Amin N, Dozor AJ. Effects of administration of aerosolized recombinant human deoxyribonuclease on resting energy expenditure in patients with cystic fibrosis. Pediatr Pulmonol 1994; 18: 150-154.

22 Boogaard H, Borgman F, Kamminga J, et al. Exposure to ultrafine and fine particles and noise during cycling and driving in 11 Dutch cities. Atmos Environ 2009; 43: 4234-4242. 
23 Adams HS, Nieuwenhuijsen MJ, Colvile RN, et al. Fine particle (PM2.5) personal exposure levels in transport microenvironments, London, UK. Sci Total Environ 2001; 279: 29-44.

24 Peters A, von Klot S, Heier M, et al. Exposure to traffic and the onset of myocardial infarction. $N$ Engl J Med 2004; 351: 1721-1730.

25 Zuurbier M, Hoek G, Oldenwening M, et al. Respiratory effects of commuters' exposure to air pollution in traffic. Epidemiology (Cambridge, Mass) 2011; 22: 219-227.

26 Larsson BM, Sehlstedt M, Grunewald J, et al. Road tunnel air pollution induces bronchoalveolar inflammation in healthy subjects. Eur Respir J 2007; 29: 699-705.

27 Cole-Hunter T, Jayaratne R, Stewart I, et al. Utility of an alternative bicycle commute route of lower proximity to motorised traffic in decreasing exposure to ultra-fine particles, respiratory symptoms and airway inflammation - a structured exposure experiment. Environ Health 2013; 12: 29.

28 Saksena S, Quang TN, Nguyen T, et al. Commuters' exposure to particulate matter and carbon monoxide in Hanoi, Vietnam. Transp Res Part D 2008; 13: 206-211.

29 Chan LY, Lau WL, Lee SC, et al. Commuter exposure to particulate matter in public transportation modes in Hong Kong. Atmos Environ 2002; 36: 3363-3373.

30 Chan LY, Lau WL, Zou SC, et al. Exposure level of carbon monoxide and respirable suspended particulate in public transportation modes while commuting in urban area of Guangzhou, China. Atmos Environ 2002; 36: 5831-5840.

31 Kaur S, Nieuwenhuijsen M, Colvile R. Personal exposure of street canyon intersection users to PM2.5, ultrafine particle counts and carbon monoxide in Central London, UK. Atmos Environ 2005; 39: 3629-3641.

32 Briggs DJ, de Hoogh K, Morris C, et al. Effects of travel mode on exposures to particulate air pollution. Environ Int 2008; 34: 12-22.

33 Gulliver J, Briggs DJ. Journey-time exposure to particulate air pollution. Atmos Environ 2007; 41: 7195-7207.

34 Zhao L, Wang X, He Q, et al. Exposure to hazardous volatile organic compounds, PM10 and CO while walking along streets in urban Guangzhou, China. Atmos Environ 2004; 38: 6177-6184.

35 Int Panis L, de Geus B, Vandenbulcke G, et al. Exposure to particulate matter in traffic: a comparison of cyclists and car passengers. Atmos Environ 2010; 44: 2263-2270.

36 Hegewald MJ, Crapo RO. Socioeconomic status and lung function. Chest 2007; 132: 1608-1614.

37 Rose G. Sick individuals and sick populations. Int J Epidemiol 1985; 14: 32-38.

38 Gong P, Liang S, Carlton EJ, et al. Urbanisation and health in China. Lancet 2012; 379: 843-852.

39 Yang G, Wang Y, Zeng Y, et al. Rapid health transition in China, 1990-2010: findings from the Global Burden of Disease Study 2010. Lancet 2013; 381: 1987-2015. 